\title{
O ZWOKALIZOWANYCH I NIEZWOKALIZOWANYCH FORMACH WYRAZÓW ZE/Z I WE/W
}

\section{WPROWADZENIE}

Wariantywność niektórych przyimków polskich - a jak to dalej pokażę, także jednej partykuły - od dawna sprawia trudności, a ich opis w wydawnictwach poprawnościowych wydaje się nieścisły i niekompletny. Chodzi o wyrazy, o których we Wstępie do II wydania SGJP [Saloni 2012, 129] pisze się tak:

Niektóre przyimki mają warianty uwarunkowane kontekstowo, np.:

(14) Zagra dziś z tobą, a nie ze mną.

Uwarunkowanie to jest dosyć skomplikowane: po części fonetyczne, po części leksykalne.

Postać zwokalizowana przyimków (we, ze, ode, pode, nade, przede itd. ${ }^{1}$ ) wiąże się (obligatoryjnie!) $z$ formami leksemu JA (mnie i mna), niesylabiczną formą zaimka on (w jednolitych słowach graficznych, przede wszystkim: bezeń, naden, odeń, podeń, przeden, przezeń, spodeń, sprzedeń, weń, zeń, znadeń, które traktujemy jako wykładniki dwu form wyrazowych; potencjalnie jest jeszcze kilka innych, niepotwierdzonych w tekstach $^{2}$ ) oraz w kilku wyrażeniach o charakterze połaczeń frazeologicznych (przede wszystkim przede wszystkim i nade wszystko; poza tym np. patrzy spode łba, zbaw nas ode $z_{\text {łego }}^{3}$ ). Ponadto formy zwokalizowane przyimków $w$ i $z$ : we i ze występuja przed słowami zaczynającymi się od grup spółgłoskowych (w mówionym wariancie polszczyzny), których część początkowa jest bliska szczelinowej [v]/[f] (np. we Wro-

1 A także: beze, ponade, popode, przeze, poprzeze, spode, sponade, spopode, sprzede, znade.

2 Znalazłem jeszcze dwa przypadki użycia formy poprzezeń [Stanisław Brzozowski, Widma moich współczesnych oraz Ludwik Stomma, Królów polskich przypadki].

${ }^{3}$ A także: we dworze (choć $w$ dworze spotykane trochę częściej), ze dworu (częstsze $z$ dworu), frazeologizm fora ze dwora!, we mszy, we krwi, ze Lwowa, we czci, we łzach, we łbie oraz nade dniem (w znaczeniu „nad ranem”). 
clawiu, ale $z$ Wrocławia) ${ }^{4}$ lub $[\mathrm{z}] /[\mathrm{s}]^{5}$ (np. ze Rzgowa, ze Zwolenia, ale $w$ Zwoleniu); ${ }^{6}$ istnieją też różnice regionalne, np. w(e) wodzie z(e) sokiem [por. Bajerowa 1950].

Konstatacja ta jest niedokładna. Odnosi się do niewielkiej grupy nietypowych leksemów nieodmiennych, majacych warianty, które mogą być uważane za fleksyjne. Widać przy opracowaniu tych haseł nie przeprowadzono dostatecznie głębokiej analizy, nawet w materiale dostępnym w słownikach. Wskażemy tu wyraźne usterki SGJP - z nadzieją, że zostaną one usunięte w następnych wersjach słownika. ${ }^{7}$

Przede wszystkim należy wymienić jeszcze jedna grupę leksemów, łączących się $z$ wokalicznym wariantem omawianych słów (rozszerzonym o -e, np. we i ze), mianowicie liczebniki DWA, TRZY, CZTERY (a w węższym zakresie także sZEŚć i SIEDEM) oraz pochodnych. Ze względu na ograniczony zakres zjawiska wyjątkowe połączenia $z$ forma rozszerzona powinny być podane w hasłach słownikowych, a nie tylko w opisie ogólnym we wstępie. Dotyczy to dwóch leksemów: $z$ i w. Przyjrzyjmy się im dokładniej.

\section{$Z E / Z$}

W opisie tej jednostki SGJP zawiera niewątpliwy błąd (niewystępujacy $\mathrm{w}$ innych opracowaniach, a wykraczajaccy poza analizowany problem główny: wariantu wokalicznego) - jednostka $z$ to dla SGJP przyimek, wyrażający „towarzyszenie, kierunek lub przybliżenie N. (z żona), D. (z domu), B. (z godzinę)". Inne słowniki rząd przyimka $z$ ograniczają do narzędnika i dopełniacza (różne znaczenia zwiazane $z$ formami rządzonymi są oczywiste, mają też różne pochodzenie), natomiast nie opisują rządu biernikowego.

Połączenia $z / z e z$ biernikiem niewatpliwie występuja (mają nawet wyraźna przewagę nad innymi), jednak nie ilustrują wcale rządu biernikowego. $\mathrm{Na}$ początek zauważmy, że fraza $z$ forma $z / z e$ oznaczająca przybliżenie może zajmować też pozycję mianownikową, np. w zdaniach [NKJP1800]:

4 Przed słowami rozpoczynajacymi się od głoski [w] forma ze może pojawić się wówczas, gdy następna głoska jest [s] (np. ze wschodu, ze wstrętem), [sz] (ze wszystkimi), [z] (ze względu, ze wzmożonym), lecz oprócz wyrażenia ze wsi, raczej nie [ś] (z rzadka spotyka się zwroty typu ze wściekłościa).

5 Do tej grupy głosek należy zaliczyć też [ź] (np. ze źródeł), [ż] (ze Żnina), [ś] (ze śniegu), [sz] (ze szkoły).

6 Forma we przed takimi słowami pojawia się sporadycznie w sfrazeologizowanych zwrotach: we śnie, we znaki, a w polszczyźnie mówionej często słyszy się: we środę (132 wystapienia w NKJP300).

7 Być może w chwili ukazania się tego tekstu będą już one usunięte, bo podczas pisania artykułu kwestię tę dyskutowałem $z$ profesorem Zygmuntem Salonim, współautorem SGJP.

8 Przykłady, których źródło nie jest podane wprost, pochodzą z Narodowego Korpusu Języka Polskiego - zrównoważonego (NKJP300) lub pełnego (NKJP1800). 
Muszą teraz minąć ze dwa miesiące, zanim przyzwyczają się...

Tam przy barze siedzi teraz $z$ dziesięciu facetów.

Obok nas stało jeszcze ze czterech zastraszonych kolesi...

Przykłady te stanowią wystarczający argument przeciw rządowi biernikowemu (propozycje innej, nieprzyimkowej interpretacji tego leksemu przedstawię niżej). Na marginesie odnotujmy, że podobnego przykładu „mianownikowego" nie znaleźliśmy w żadnym słowniku. Są w nich natomiast przykłady użycia konstrukcji ze słowem $z$ lub ze w pozycji innego przypadka - celownika:

Zapewnili prace ze stu absolwentom... [ISJP].

Wszystkim nie dam rady, ale ze czterem osobom dam rade wysłać $15 \mathrm{z}$ w tym miesiacu.

O cytaty $z$ takimi (niebiernikowymi i niemianownikowymi) wyrażeniami w ogóle trudno. Wszystkie przykłady na użycie takiego $z(e) \mathrm{w}$ odpowiednich hasłach przejrzanych przez nas słowników nie notuja jego użycia w innych przypadkach, jednak można je znaleźć w tekstach lub skonstruować, np.:

Kierował dotychczas już ze setka firm (narzędnik).

Nie brakuje ze dwóch zer w tej liczbie?

któremu brakuje z sześciu zębów ${ }^{9}$ (dopełniacz).

Słowniki na ogół notuja przykłady $z$ fraza wprowadzana przez z(e) w bierniku - i takie stanowią większość.

W tekstach napotkać można pozorne kontrprzykłady, w których na pozycji dopełniaczowej występuje ze + biernik, np.:

* jeszcze mu brakuje ze trzy stopnie do Dudy, ${ }^{10}$

lecz chyba należy je uznać za niepoprawne.

Użycia w przypadkach syntetycznych podałem wyżej, jednak najciekawsze sa te, w których „adnumeratywne” z(e) występuje po przyimku, np.:

a w ze czterdziestu nawet zamontowano żarówki; ${ }^{11}$

Mieszkalismy chyba w ze dwudziestu stanach; ${ }^{12}$

$i$ włóczy $z$ nim po ze sześciu magazynach $z$ moda męska. ${ }^{13}$

9 Brent Weeks, Oślepiajacy nóż.

10 Wiesław Myśliwski, Drzewo.

11 Anna Blundy, Czysta wódka.

12 Jeffery Deaver, Spirale grozy.

13 Stephen King, Czarny dom. 
Konstrukcja $z$ z(e) występuje tu po przyimku o rządzie miejscownikowym. Możliwe jest też użycie narzędnikowe, i to po przyimku z(ze):

wraz $\underline{z} z$ piecioma innymi osobami jechat ekspresowa winda. ${ }^{14}$

Występuje tu więc sąsiedztwo dwu jednostek homonimicznych (ściślej, akurat wystapiły różne formy leksemów, mających wszystkie formy homonimiczne).

Interpretacja, że jest to rząd biernikowy, występuje tylko w SGJP. Nie jest ona dobra - w takim użyciu z(e) nie może być uznane za przyimek (nie ma rządu). Pozostaje kwestia zaliczenia go do odpowiedniej klasy leksemów.

Na przykład w Słowniku wyrazów trudnych $i$ kłopotliwych w artykule „W, we, $z$, ze itp.” czytamy m.in.:

(...) a także w funkcji partykuły, np. Zjadł ze trzy talerze zupy.

W zdaniu tym po ze występuje niewątpliwy biernik, ale słowo to uznane jest za partykułę. Przyjrzyjmy się przykładom w innych słownikach.

W Innym słowniku języka polskiego mamy wyodrębnione hasło z 2. („partykuła”):

$\mathbf{z}, \mathbf{z e}$ (PART PREP + L GE/RZ ${ }^{15}$; =mniej więcej). Forma ze występuje przed wyrazami „dwa”, „dwanaście”, „dwadzieścia”, „dwieście”, „trzy”, „trzynaście”, „trzydzieści”, „trzysta”, „cztery”, „czternaście”, „czterdzieści”, „czterysta” i „sto”. Użycie formy $z \mathrm{w}$ tych kontekstach ( $z$ wyjątkiem pozycji przed "sto") jest też możliwe, ale rzadsze. Słowem $z$ poprzedzamy określenie liczby, ilości lub czasu, aby zaznaczyć, że jest ono przybliżone. Kup ze dwa kilo kartofli... Zapewnili prace ze stu absolwentom... Siedziała u dentysty chyba z godzinę... Ten drugi mógł mieć już ze czterdziestkę.

Niedokładność SGJP dotyczy nie tylko wariantu ze, ale całego leksemu. Lepszy podział znaczeń był już w SJPDor., w którym leksem II $z$ (I $z$ to nazwa litery, a ze opisane jest w osobnym haśle) ma wyodrębnione trzy znaczenia: 1. Przyimek $z$ rzeczownikami w dopełniaczu, 2. Przyimek z rzeczownikami w narzędniku 3. Wyraz towarzyszacy określeniom wielkości, miary, wprowadzający odcień niedokładności, oceny przybliżonej (podobnie jest zbudowane to hasło w trzytomowym SJP PWN, tylko w ostatnim znaczeniu jest „wyraz pełniący funkcję przysłówka, towarzyszący określeniu wielkości (...)". USJP nie powtarza kwalifikacji z jako przysłówka, wyodrębnia III z „pot. "partykuła poprzedzająca określenie liczby, ilości lub czasu; komunikuje, że jest ono przybliżone;

14 „Wprost”, 20 stycznia 2002 r. [https://www.wprost.pl/swiat/22604/Polski-bohater-z-WTC.html].

15 Symbole te oznaczaja: partykuła prepozycyjna poprzedzająca liczebnik główny lub rzeczownik. 
mniej więcej”" oraz II ze "pot. to samo co III z”). Wszystkie przykłady (z z) w SJPDor. zawierają frazę biernikową, większość jest $z$ formami rzeczowników ( $z$ godzine, $z$ garniec, $z$ mile) , jedyne liczebnikowe to: $z$ pięć, z jakie sto kańczugów). Osobne hasło ze zawiera pośrednie odesłanie do II $z$ : „to samo co z" i szczegółową analizę, kiedy występuje ten wariant - wyłącznie w uwarunkowaniach fonetycznych. Nie ma żadnego przykładu na ze $\mathrm{z}$ forma liczebnikowa. ${ }^{16}$

To istotne uwarunkowanie strukturalne nie zostało również zauważone przez kolejne mutacje słownika poprawnej polszczyzny, aż do WSPP:

II $\mathbf{z}$ partykuła łaczaca się z rzeczownikami i liczebnikami, pot. "około, mniej więcej”: Przeszliśmy już z pięć kilometrów. To mi zajmie jeszcze $z$ godzinkę.

ze "forma partykuły: $z$, używana najczęściej przed wyrazami zaczynajacymi się od grupy spółgłosek»: dostaniesz za to ze dwa tysiące. Zatrudni ze trzydziestu mężczyzn.

Wielki słownik języka polskiego dla hasła „z" w znaczeniu „18. z trzy”17 podaje m.in.:

Odmiana: część mowy: operator metapredykatywny, podklasa: operator aproksymacji. Składnia: w pozycji prawostronnej: Licz., Rz. odliczebnikowy, Rz. nazywający jednostkę miary konwencjonalną lub niekonwencjonalną

Kategoria znaczeniowa: wykładnik kwantyfikacji ilościowej.

Noty o użyciu: $Z$ wyrazami zaczynającymi się od co najmniej dwóch spółgłosek, z których pierwsza to: $z, s, \dot{z}, s z, \dot{z}, s ́$ występuje wariant $z e$. Wariant ze może wystapić także przed innymi wyrazami, w szczególności zaczynającymi się od co najmniej dwóch spółgłosek.

Zauważmy, że w SWTiK we fragmencie dotyczacym takich połączeń pisze o „partykule”. Maciej Grochowski w Wyrażeniach funkcyjnych [Grochowski 1997] uściśla to pojęcie [za: Wróbel 1991; 1995], dołączając z do grupy tzw. „operatorów adnumeratywnych”. Ich cechą - w odróżnieniu od przyimków - jest to, że nie wprowadzają one własnego rządu przypadka.

W SGJP $z$ jest wyłącznie przyimkiem, choć dla np. OKOŁo i PONAD obok leksemu przyimkowego mamy w SGJP homonimiczne leksemy opisane jako operatory adnumeratywne. ${ }^{18}$

16 Przykłady takie pojawiły się dopiero w ISJP (w cytacie wyżej), a potem w USJP.

17 http:/ / wsjp.pl/index.php?id_hasla=29541\&id_znaczenia=5111227\&l=2 9\&ind $=0$

18 Profesor Zygmunt Saloni po przeczytaniu szkicu tego artykułu odpowiedział mi: Pana przykłady z ze przekonały mnie ostatecznie, że kwalifikacja w SGJP z(e) przybliżonego jako przyimka jest niewłaściwa, a racje maja słowniki, które twierdza inaczej (oczywiście na partykułe można się zgodzić tylko wtedy, jeśli partykuły to klasa resztkowa). A więc „operator adnumeratywny”. A to zmienia nasz (i nie tylko) poglad, że warianty wokaliczne ograniczone sa do przyimków. 
Na nieprzyimkowe $z$ nie zgodziłaby się pewnie też Halina Jadacka, która nie godzi się na nieprzyimkowe użycia окоєо i PONAD [Jadacka 2005, 198 i 218].

Mimo tych kontrowersji formułujemy:

Wniosek 1. Wyraz $z / z e$, wskazujący na przybliżenie wartości liczbowej, nie wymaga przypadka następującego po nim wyrazu; przypadek ten jest dostosowany do wymagania czasownika lub przyimka, nadrzędnego wobec całego wyrażenia.

Wynika $z$ tego, że wyrazy $z / z e$ moga występować w funkcji operatora adnumeratywnego, ${ }^{19}$ a to oznacza, że kategoria wokaliczności może mieć zastosowanie także w odniesieniu do tej klasy wyrazów. Fakt ten powinny uwzględniać analizatory morfologiczne, np. analizator Morfeusz, który obecnie [Woliński 2019, 43] kategorię fleksyjną wokaliczności przewiduje m.in. dla przyimków, lecz nie dla partykuł.

Spróbujemy jeszcze odpowiedzieć na pytania:

1. Które liczebniki łączą się $z$ formą zwokalizowaną $z e$ ?

2. Czy jej użycie w połączeniu $z$ liczebnikiem zawsze oznacza przybliżoność?

3. Czy dla tych liczebników przybliżenie może być wyrażane z użyciem niezwokalizowanej formy $z$ ?

Odpowiedź na pierwsze pytanie łatwo znajdujemy, przeglądając dane frekwencyjne NKJP300 ${ }^{20}$ dla par wyrazów postaci $z / z e+$ forma liczebnika.

$Z$ poniższego zestawienia (tabela 1.) wynika, że formę ze spotyka się regularnie $\mathrm{w}$ połączeniu $z$ liczebnikami DWA, TRZY, CZTERY, ich dziesięcioi stukrotnościami, rzadziej w wypadku liczebnika szEść, a sporadycznie też SIEDEM, i ich pochodnych.

$Z$ rzadka w parze ze zwokalizowanym ze spotyka się derywowane od liczebników DWA, TRZY, CZTERY rzeczowniki typu DWÓJKA, TRÓJKA, CZWÓRKA, DWUNASTKA itp. oraz przymiotniki typu TRZYKROTNY, DWUSTUMETROWY. Warto zwrócić uwagę na użycie formy zwokalizowanej w zestawieniu $z$ liczebnikami SZEŚĆ i SIEDEM (ISJP i WSJP nie wskazują na taką możliwość).

19 Operatory adnumeratywne w tradycyjnej terminologii zaliczane sa do partykuł.

20 Takie dane $z$ Narodowego Korpusu Języka Polskiego dostępne sa w postaci tzw. N-gramów [http://zil.ipipan.waw.pl/NKJPNGrams]. 


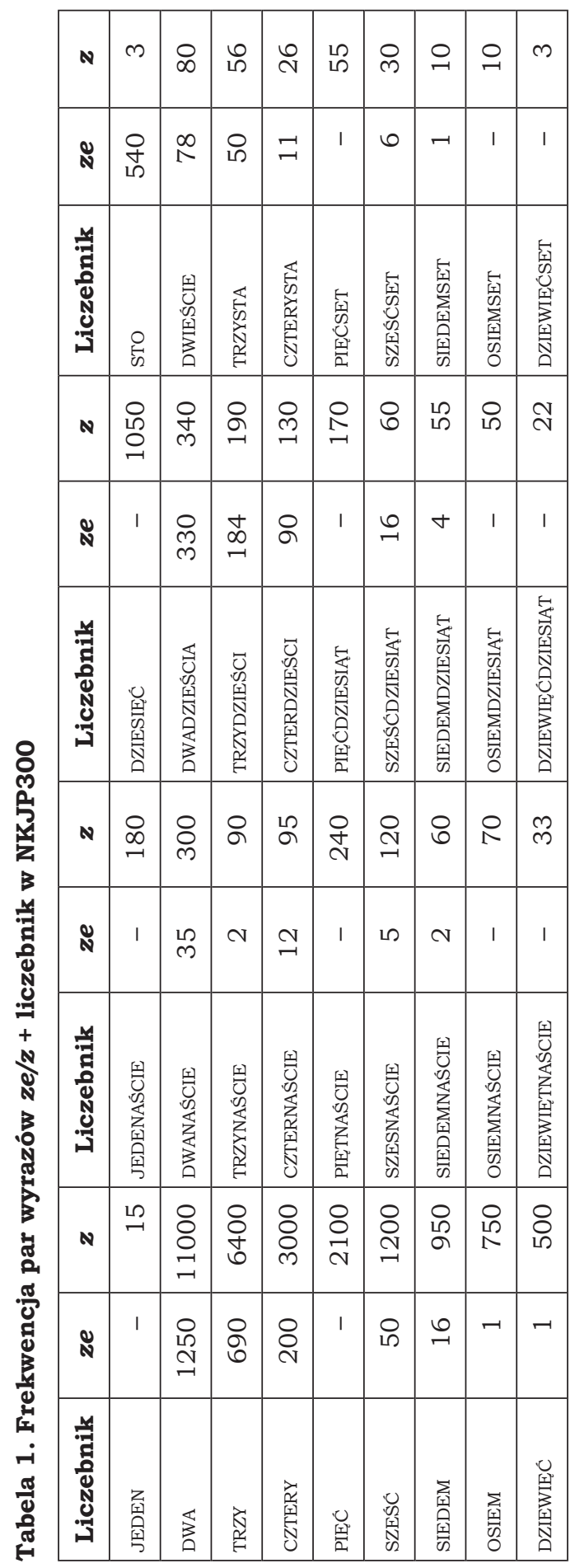


Wniosek 2. Ze zwokalizowana formą ze łączą się formy liczebników sTo, DWA, TRZY, CZTERY, rzadziej SZEŚĆ i SIEDEM oraz ich derywatów.

$\mathrm{W}$ tabeli 1 . uwzględniono wszystkie formy badanych leksemów. Aby odpowiedzieć na drugie pytanie, powinniśmy zbadać frekwencję poszczególnych ich form. Przykładowo frekwencja połaczenia $z / z e$ z formami liczebnika TRZY przedstawia się następująco:

Tabela 2. Frekwencja polączeń ze/z + forma TRZY w NKJP300

\begin{tabular}{|c|c|c|c|}
\hline $\begin{array}{c}\text { Forma } \\
\text { (segment) }\end{array}$ & $\begin{array}{c}\text { Możliwe przypadki } \\
\text { formy }\end{array}$ & Frekwencja z ze & Frekwencja z z \\
\hline trzy & M., B. & 619 & 43 \\
\hline trzech & M., D., B., Ms. & 23 & 4718 \\
\hline troje & M., B. & 2 & - \\
\hline trojga & D. & - & 44 \\
\hline trojgiem & N. & - & 105 \\
\hline trzema & N. & - & 1425 \\
\hline
\end{tabular}

Z powyższej tabeli widać, że forma zwokalizowane ze nie wystapiła $\mathrm{w}$ parze $\mathrm{z}$ forma dopełniacza trojga i $\mathrm{z}$ formami narzędnika trojgiem, trzema. Przeglądając konkretne cytaty w NKJP dla wyrażenia ze trzech, można stwierdzić, że we wszystkich wypadkach ma ono kontekst biernikowy lub mianownikowy i wyraża przybliżenie.

Podobne rozkłady frekwencji form mamy dla innych liczebników łączacych się ze zwokalizowanym ze.

Wyjątkowy jest pod tym względem liczebnik sTo, którego formy (sto, stoma, stu) łączą się w zasadzie tylko $z$ formą zwokalizowana. Ma to jednak swoje uzasadnienie fonetyczne:

Tabela 3. Frekwencja par wyrazów $z e / z+$ forma sTo w NKJP300

\begin{tabular}{|c|c|c|c|}
\hline $\begin{array}{c}\text { Forma } \\
\text { liczbowa }\end{array}$ & $\begin{array}{c}\text { Możliwe przypadki } \\
\text { formy }\end{array}$ & Frekwencja z ze & Frekwencja z z \\
\hline sto & M., B. & 278 & 1 \\
\hline stu & wszystkie & 253 & 2 \\
\hline stoma & N. & 3 & - \\
\hline
\end{tabular}

W takich zdaniach jak np.:

Obok leżała teczka ze stoma tysiącami dolarów.

Jedna ze stu pięćdziesięciu.

Pierwiastek ze stu? 
forma ze oczywiście przybliżenia nie oznacza. Jak już wspomniałem, jej wystapienie jest uzasadnione fonetycznie.

Wniosek 3. Zwokalizowana forma ze $\mathrm{w}$ połączeniu $z$ liczebnikiem oznacza przybliżenie. Jedynie w wypadku liczebnika sTo połączenie takie przybliżenia oznaczać nie musi.

Z tabeli 2. - dla liczebnika TRZY - widać też, że biernikowe lub mianownikowe $z$ trzy ma dość znaczna frekwencję. Przegląd konkretnych cytatów $z$ tym wyrażeniem pozwala stwierdzić, że w wielu wypadkach wyraz $z$ oznacza w nich przybliżenie, np.:

Staliśmy tak $\mathrm{z}$ trzy przyśpiewki.

Gość musi mieć z trzy metry bez hełmu.

Użycie takiej formy niezwokalizowanej $z$ innymi liczebnikami jest oczywiste (zob. tabela 1.).

Wniosek 4. Przybliżenie może być wprowadzane z użyciem niezwokalizowanej formy $z$ nawet w wypadku liczebników, które łączą się głównie $z$ forma zwokalizowaną.

\section{WE/W + LICZEBNIK ${ }^{21}$}

W wspomnianym już artykule „W, we, z, ze itp.” SWTiK stwierdza:

Czasem postaci z końcowym -e i bez -e moga być używane wymiennie, np. we trzech lub w trzech (...).

W Innym słowniku języka polskiego pod hasłem „w, we” w punkcie 24. czytamy:

(PI $[\mathrm{B}]^{22}$ ). Jeśli ludzie robią coś we dwoje, we troje itp., to robia to w grupie dwuosobowej, trzyosobowej itd. Śpimy we trójkę na jednym łóżku... ...romantyczna podróż we dwoje.

Podobnie WSPP pod hasłem „we” podaje:

We dwie (w grupie dwu kobiet, dziewczat), ale: w dwie strony świata. We trzech, we czterech (...), ale: (powieść) w trzech, czterech tomach.

21 Poza właściwymi liczebnikami mówimy tu też o tzw. numeroidach - wyrazach o funkcji zbliżonej do liczebnika, lecz formalnie nimi niebędących, np. dwójka, piątka, tuzin.

22 Symbole te oznaczają: przyimek $z$ rządem biernikowym. 
WSJP dla hasła „w” w znaczeniu „23. w trójkę"23 podaje m.in.:

Odmiana: część mowy: przyimek

Składnia: w KOGO/CO; w pozycji prawostronnej: Rz. kolektywny oznaczający liczebność grupy

Kategoria znaczeniowa: wykładnik ilości.

Noty o użyciu: W połączeniu $z$ wyrazami zaczynającymi się od co najmniej dwóch spółgłosek może wystapić wariant we, jednak takie użycie może być nacechowane stylistycznie.

W podanym przykładzie $z$ SWTiK pojawia się liczebnik TRZY w niejednoznacznym przypadku gramatycznym, bo przyimek $w$ może rządzić miejscownikiem lub biernikiem (tak też w SGJP), a forma trzech odpowiada obu tym przypadkom. Formy we dwoje, troje, trójkę sa już jednoznacznie biernikowe. Rząd biernikowy jawnie wskazuje ISJP.

Pojawia się pytanie: jakie jeszcze liczebniki (i ich derywaty) moga łączyć się ze zwokalizowana forma we oraz czy wymienność formy przyimka dotyczy tylko wariantu rządzącego biernikiem? A może sa jeszcze jakieś inne ograniczenia dotyczace użycia formy zwokalizowanej? W pierwszej kolejności pomocne moga tu być dane o frekwencji takich par ( $w / w e+$ liczebnik) w NKJP300.

$Z$ forma zwokalizowana we spotyka się zasadniczo tylko liczebniki DWA, TRZY, CZTERY i pochodzące od nich rzeczowniki DWÓJKA, TRÓJKA, CZWÓRKA.

$Z$ poniższej tabeli frekwencyjnej wynika, że we nie pojawia się w parze $z$ formami miejscownika - najlepiej widać to na przykładzie frekwencji form dwójce, trójce, czwórce.

Tabela 4. Frekwencja w NKJP300 par wyrazów we/w + formy wybranych liczebników

\begin{tabular}{|c|c|c|c|c|}
\hline \multirow{2}{*}{ Leksem } & $\begin{array}{c}\text { Forma } \\
\text { (segment) }\end{array}$ & Możliwe przypadki & $\begin{array}{c}\text { Frekwencja } \\
\mathbf{z} \text { we }\end{array}$ & $\begin{array}{c}\text { Frekwencja } \\
\mathbf{z} \boldsymbol{w}\end{array}$ \\
\hline \multirow{7}{*}{ DWA } & $d w a$ & M., B. & 40 & 2000 \\
\cline { 2 - 5 } & dwie & M., B. & 200 & 700 \\
\cline { 2 - 5 } & dwoje & M., B. & 700 & 4 \\
\cline { 2 - 5 } & dwóch & wszystkie oprócz N. & 400 & 9000 \\
\cline { 2 - 5 } & dwu & Wszystkie & 20 & 400 \\
\cline { 2 - 5 } & dwojgu & C., Ms. & 0 & 3 \\
\hline
\end{tabular}

${ }^{23} \mathrm{http}: / /$ wsjp.pl/index.php?id_hasla=242888id_znaczenia $=5209553 \& 1$ $=278$ ind $=0$ 


\begin{tabular}{|c|c|c|c|c|}
\hline Leksem & $\begin{array}{c}\text { Forma } \\
\text { (segment) }\end{array}$ & Możliwe przypadki & $\begin{array}{c}\text { Frekwencja } \\
\text { z we }\end{array}$ & $\begin{array}{c}\text { Frekwencja } \\
\qquad z w\end{array}$ \\
\hline \multirow{2}{*}{ DWÓJKA } & dwójkę & B. & 350 & 50 \\
\hline & dwójce & C., Ms. & 0 & 77 \\
\hline \multirow{4}{*}{ TRZY } & trzy & M., B. & 60 & 1000 \\
\hline & trzech & M., B., Ms. & 200 & 5000 \\
\hline & troje & M., B. & 190 & 3 \\
\hline & trojgu & C., Ms. & 0 & 0 \\
\hline \multirow{2}{*}{ TRÓJKA } & trójkę & B. & 420 & 300 \\
\hline & trójce & C., Ms. & 0 & 63 \\
\hline \multirow{4}{*}{ CZTERY } & cztery & M., B. & 20 & 1100 \\
\hline & czterech & M., B., Ms. & 60 & 2300 \\
\hline & czworo & M., B. & 100 & 20 \\
\hline & czworgu & C., Ms. & 0 & 0 \\
\hline \multirow{2}{*}{ CZWÓRKA } & czwórke & B. & 110 & 120 \\
\hline & czwórce & C., Ms. & 0 & 100 \\
\hline
\end{tabular}

Wniosek 5. Forma zwokalizowana we w połączeniu $z$ formami liczebników (i ich derywatów) występuje tylko w wariancie $z$ biernikiem liczebników DWA, TRZY, CZTERY oraz pochodzących od nich rzeczowników DWÓJKA, TRÓJKA, CZWÓRKA.

Pozostaje pytanie, czy w takich wypadkach wybór formy przyimka zwokalizowanej lub nie - nie jest uwarunkowany kontekstem składniowym lub znaczeniowym?

Przyglądając się użyciu przykładowo wyrażenia we trzy (60 wystąpień w NKJP300), np.:

Usiadty teraz we trzy przy stole $i$ ogladały zdjecia.

My we trzy siedziałyśmy na ławeczce, a Jerzy wiosłowat.

Iskra, Mistle i Falka we trzy, jak tu siedza, przejechały $w$ biały dzień środkiem miasteczka.

Gralismy we trzech.

możemy zauważyć, że we wszystkich wypadkach fraza ta pełni funkcję okolicznika i nie ma żadnych podrzędników - dotyczy domyślnych lub osobno wymienionych osób. ${ }^{24}$

24 Określenie „osób” można rozszerzyć do „elementów grupy”, bo „we trzy” może być też odpowiedzią np. na pytanie „w ile koni / samochodów jedziecie?”. 
Frazy typu we trzy, $z$ tym samym zastrzeżeniem, moga wystapić $\mathrm{w}$ funkcji dopowiedzeń w odpowiedzi na pytanie „w ile osób?”.

$Z$ kolei wyrażenie $w$ trzy (tysiąc wystąpień w korpusie), np. w zdaniach:

Przynajmniej dwa razy dziennie w trzy osoby pokonujemy tę trasę.

Zdążymy w trzy godziny dojść i wrócić.

Tłum gapiów uformował się w trzy grupy.

uzupełniane jest o podrzędniki.

Nie mielibyśmy raczej zastrzeżeń poprawnościowych do fraz typu Usiadly teraz $\underline{w}$ trzy przy stole ( $z$ niezwokalizowanym $w$ i bez podrzędników liczebnika), lecz takich konstrukcji nie znalazłem w NKJP. ${ }^{25}$

Prawie nie spotyka się też wypowiedzi typu:

* We trzech grach uzbieraliśmy tylko 10 punktów,

które już jednak odczuwamy jako niepoprawne. ${ }^{26}$

Wniosek 6. Forma zwokalizowana we w połaczeniu $z$ liczebnikami nie może być rozszerzana o podrzędniki i ograniczona jest do funkcji okolicznika lub dopowiedzenia określającego liczbę osób (liczebność grupy).

\section{WNIOSKI KOŃCOWE}

Przedstawione powyżej tezy powinny być, moim zdaniem, uwzględnione $\mathrm{w}$ pogłębionym opisie leksykograficznym omawianej grupy wyrazów i moga być też przydatne przy rygorystycznym, sformalizowanym opisie składni dla potrzeb automatycznej analizy składnikowej, np. dla analizatora Świgra 2 [Woliński 2019].

\section{PODZIĘKOWANIA}

Najuprzejmiej dziękuję prof. Zygmuntowi Saloniemu, który zechciał zapoznać się $z$ artykułem w trakcie jego powstawania i podzielił się ze mną swoją opinią oraz szeregiem ważkich wskazówek i rad.

25 W wyszukiwarce korpusowej NKJP300 zapytanie: „w trzy [pos!=”subst” \& pos!="conj" \&pos!="adj"]" daje 49 wyników, lecz żaden $z$ nich nie reprezentuje konstrukcji omawianego typu.

26 Fraza „w cztery konie” 51 razy pojawia się w NKJP1800, a „we cztery konie" tylko raz, ale... w Potopie H. Sienkiewicza: Kowalski zatrzymał konwój i więźniów przed ogromnym wozem drabiniastym zaprzężonym we cztery konie. 
Bardzo wdzięczny jestem też anonimowej recenzentce, do której krytycznych, lecz wnikliwych i konstruktywnych uwag starałem się dostosować.

\section{Bibliografia}

I. Bajerowa, 1950, Czy wolno nam mówić „we wodzie”, „ze sokiem”?, „Język Polski" r. 30, z. 5, s. 193-203.

M. Grochowski, 1997, Wyrażenia funkcyjne. Studium leksykograficzne, Kraków. ISJP: M. Bańko (red.), 2000, Inny słownik języka polskiego, t. 1-2, Warszawa.

H. Jadacka, 2005, Kultura języka polskiego. Fleksja, słowotwórstwo, składnia, Warszawa.

NKJP: Narodowy Korpus Języka Polskiego [online: http://nkjp.pl/].

Z. Saloni, 2012, Podstawy teoretyczne „Słownika gramatycznego języka polskiego", Warszawa (także: http://sgjp.pl/static/pdf/Wstęp\%20do\%20II\%20 wydania\%20SGJP.pdf).

SGJP: Z. Saloni, M. Woliński, R. Wołosz, W. Gruszczyński, D. Skowrońska, 2015, Słownik gramatyczny języka polskiego, wyd. III online, Warszawa [http://sgjp.pl].

SJPDor.: W. Doroszewski (red.), Słownik języka polskiego [online: http://www. sjpd.pwn.pl].

SJP PWN: M. Szymczak (red.), 1981, Słownik języka polskiego, Warszawa.

SWTiK: M. Bańko, 2010, Słownik wyrazów trudnych i kłopotliwych PWN, Warszawa.

USJP: S. Dubisz (red. nauk.), 2004, Uniwersalny słownik języka polskiego, Warszawa, CD wersja 1.0.

M. Woliński, 2019, Automatyczna analiza składnikowa języka polskiego, Warszawa.

WSJP: Wieki słownik języka polskiego [online: http:/ /wsjp.pl].

WSPP: A. Markowski (red.), 2004, Wielki słownik poprawnej polszczyzny, Warszawa.

\section{On vocalised and unvocalised forms of words with $\mathrm{ze} / \mathrm{z}$ and we/w}

\section{Summary}

This paper discusses the conditions of using the vocalised variants (ze and we) of the lexemes $\mathrm{z}$ and $\mathrm{w}$ as regards their co-occurrence with numeral forms on the basis of corpus data.

Keywords: vocalisation, morphology, lexicography 